\title{
Green synthesis of silver nanoparticles (Ag-NPs) from Olea dioica Roxb., leaf extracts and its biological activity
}

\author{
Pratap G. K. ${ }^{1}$ and Manjula Shantaram ${ }^{2}$ \\ ${ }^{1}$ Research scholar, ${ }^{2}$ Professor, Department of Studies and Research in Biochemistry, Mangalore University, Jnana \\ Kaveri Post Graduate Centre, Chikka Aluvara, 571 232, Kodagu, Karnataka, India
}

(Received: August $2019 \quad$ Revised: October $2019 \quad$ Accepted: December 2019)

Corresponding author: Manjula Shantaram.Email: manjula59@gmail.com

\begin{abstract}
Introduction and Aim: The silver nanoparticles have attained a special place in the area of nanotechnology because of their different biological applications. Fabrication of nanoparticles using green synthesis is done because of its wide applications in different fields such as biomedical, medicine, agriculture and food engineering. This study is to develop an easy and eco-friendly method for the synthesis of Ag-NPs using leaf extracts of the medicinal plant.

Materials and Methods: The medicinal plants are rich sources of various medicinal properties. Olea dioica Roxb., leaf extract was used to investigate the effects of Ag-NPs having antibacterial activity and antioxidant capacity. The plant leaf extract contains flavonoids, alkaloids, saponins, and phenolic compounds which acts as reducing and stabilizing agents. The green synthesized silver nanoparticles were characterized by various techniques like UVvisible spectrophotometer, FTIR spectroscopy, and SEM analysis.

Results: The synthesis of sliver nanoparticles from plant source, and analysis of nano particles by UV-Vis spectra, SEM and FTIR. The biological evaluations of Ag-NPs indicated an excellent inhibitory efficacy, antioxidant and antimicrobial activity for their future applications in medicine.

Conclusion: The synthesized silver nanoparticles exhibited potent antioxidant and antimicrobial activities against Gram-positive and Gram-negative bacteria. The silver (Ag-NPs) nanoparticles synthesized by the pot green synthesis method proves its potential use in various medical applications.
\end{abstract}

Keywords: Silver nanoparticles; Medicinal plants; Ag-NPs; Olea dioica Roxb.,

\section{INTRODUCTION}

$\mathrm{N}$ anoscience is based on the manipulation of individual molecules to manufacture materials from them for implementation well below the sub-microscopic level (1). Nanobiotechnology is a well-growing technology as an interdisciplinary ecofriendly research area today and used in broad research sections such as biology, biochemistry, chemistry, physics, biomedicine, nanomedicine, and material engineering (2). It deals with various shapes and size of nanoparticles in the range of 1 to $100 \mathrm{~nm}$. Materials in the nano-dimensions have a high surface to volume ratio that gives them some unique or similar properties that are varied from the same material in bulk which are helpful in various fields such as electronics, biomedical, photonics, etc., The nanoparticles are also utilized in the field of solar energy conversion, and water treatment. Among the various fine metals, silver is preferred as a nanoparticle because of its antibacterial catalytic activity and it has no toxicity towards human beings which is similar to other metals (4). Previously several methods have been used for the synthesis of Ag-NPs, which can be either, chemical, physical or biological methods.

Green synthesis of nanoparticles has been considered as one of the hopeful methods for synthesis of nanoparticles because of their low toxicity, biocompatibility and eco-friendly nature (3). Thus, synthesis of silver nanoparticles by eco-friendly processes using the plant materials like root, leaf extract, bark, stem, fruit latex, bud is being carried out (5).

Medicinal plants have been used from ancient times to attempt cures for various diseases. The therapeutic power of traditional herbal medicines has been realized and familiar since Rigveda and Atharvaveda. Medicinal plants are potentially renewable natural resources and are generally considered to play a beneficial role in human health care (6-8). In view of this in the present study silver nanoparticles were synthesised using leaves of Olea dioica Roxb.

Olea dioica Roxb., is an important ethno medicinal plant medicinal plant belong to Oleaceae family. It grows in open evergreen forests up to1100-1200 m and is distributed throughout the Western Ghats region of Kodagu, Dakshina Kannada, Udupi and Hassan. The plant parts such as roots, bark, and leaves are used for anti-cancer, antioxidant, and anti$\mathrm{AChE}$ activity. Although vast amount of literature is available on the green synthesis of Ag-NPs, to the best of our knowledge no information is available on the synthesis of silver nano particles using the leaves of Olea dioica Roxb., In the present investigation a 
stable and eco-friendly method has been developed for the synthesis of silver nanoparticles using methanolic extracts of Olea dioica Roxb. Thus, synthesised Ag-NPs were evaluated for their antimicrobial activities.

\section{MATERIALS AND METHODS}

\section{Chemicals}

Silver nitrate, $\left(\mathrm{AgNO}_{3}\right)$ was purchased from Himedia Ltd., India. All other chemicals used in this study were of analytical grade.

\section{Preparation of plant extract}

Olea dioica Roxb., leaves were collected from Pilikula Mangalore, Dakshina Kannada, Karnataka, India. Freshly collected leaves were washed 3-4 times with tap water and finally washed with distilled water, and shade dried at room temperature for 23 days and mechanically made a fine powder. Fifty grams of powder was extracted with methanol (12 hours) using Soxhlet extractor. The extracts were evaporated at room temperature and stored in brown bottles at room temperature until screened. This methanolic extract was used for the synthesis of silver nanoparticles.

\section{Synthesis of silver nanoparticles}

The methanol leaf extracts of Olea dioica Roxb., was used in the bio-reduction of silver ions. Five $\mathrm{ml}$ of leaf extract was taken in BOD bottle separately and was mixed with $95 \mathrm{ml}$ of $1 \mathrm{mM} \mathrm{AgNO}_{3}$ solution. The silver nanoparticles synthesized were separated by centrifugation at $10,000 \mathrm{rpm}$ for 10 minutes. The pellets were washed thoroughly at least three times with methanol, ethanol, and water to remove any biological contaminants. The particles were then dried and stored for further analysis $(6,12,13)$.

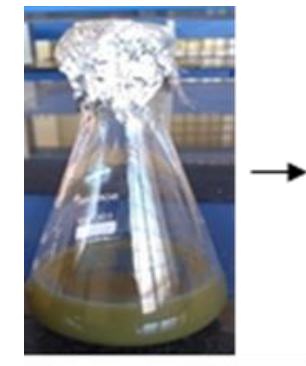

$0 \mathrm{Min}$

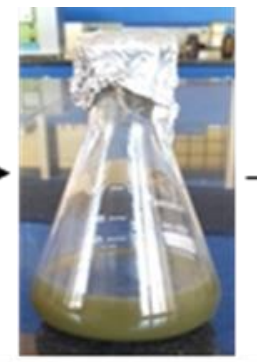

After $1 \mathrm{hr}$

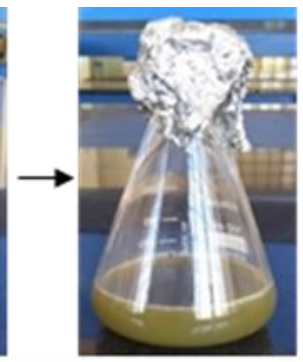

After $2 \mathrm{hrs}$

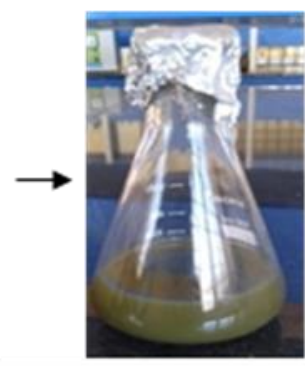

After 3hrs

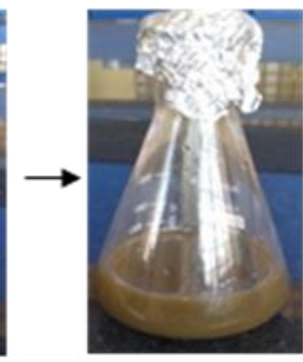

After 4 hrs

Fig.1 Colour change in the leaf extract and silver nitrate at a different time of incubation

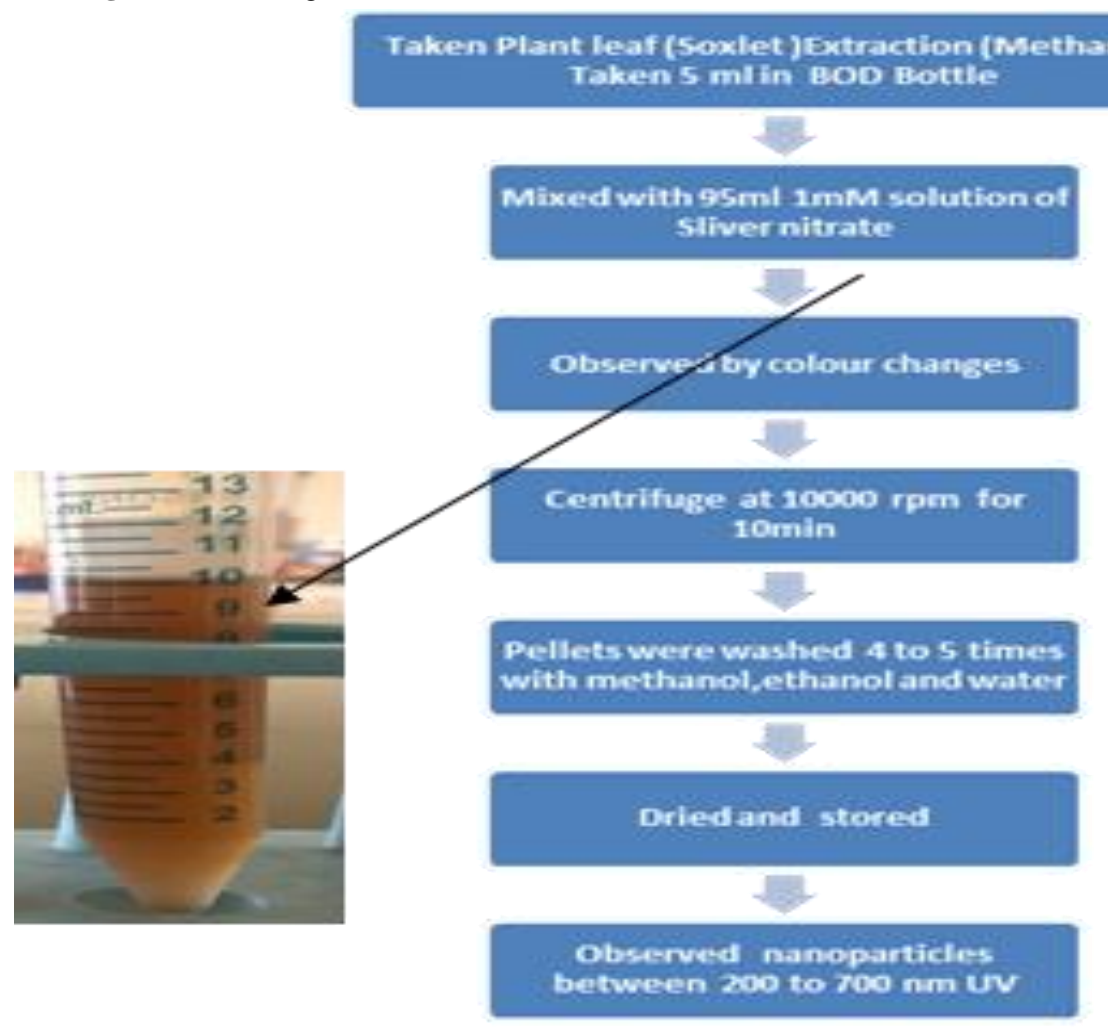

Flow-chart: 1 Change in colour of the solution with time when silver salt was added to leaf extract.

\section{Characterization of silver nanoparticles} UV-visible spectral analysis

The bio-reduction of silver nanoparticles was observed by UV-spectroscopy of the solution between 200 and $700 \mathrm{~nm}$ using (Beckman Coulter) UV-Vis spectrophotometer (14). 
Effect of different contact time on Ag-NPs concentration

The effect of different contact time on silver nanoparticles concentration in the reaction mixture at different time intervals is exhibited with a colour change of the solution. The intensity of UVabsorption peaks is gradually increased and then becomes stable because the Ag-NPs concentration is initially increased with increase in different contact time which is due to the effect of outside Plasmon character of Ag-NPs (16).

\section{FTIR (Fourier-transform infrared spectroscopy)}

For FTIR analysis, the sample was prepared by dispersing the silver nanoparticles uniformly in a matrix of $\mathrm{KBr}$ (potassium bromide). The characterization of functional groups on the silver nanoparticles the spectra was scanned in the range of 4000-500 $\mathrm{cm}^{-1}$. The intense bands were compared with standard values to identify the functional groups (15).

\section{SEM analysis}

The sample for SEM analysis was prepared by dissolving nanoparticles in $0.1 \mathrm{ml}$ of deionized water. This was placed on a glass coverslip and air-dried. The coverslip itself was used during SEM analysis (Carl Zeiss, Germany, and Model No. EVO LS 15). The images of Ag-NPs were obtained (16) in a scanning electron microscope at different nanometers $(25,50 \mathrm{~nm})$.

\section{Microbial cultures}

The microbial cultures used in the present study were obtained from Department of Microbiology, Mangalore University, PG Centre, Chikka Aluvara, Kodagu, Karnataka, India. The cultures used were pathogenic bacteria such as Escherichia coli, Staphylococcus aureus, Streptococcus sp., Proteus vulgaris, Klebsiella and Salmonella sp. The pure bacterial cultures were sub-cultured on nutrient agar media. Different concentrations of silver nano particles in distilled water were used for antibacterial activity. The zone of bacterial inhibition was

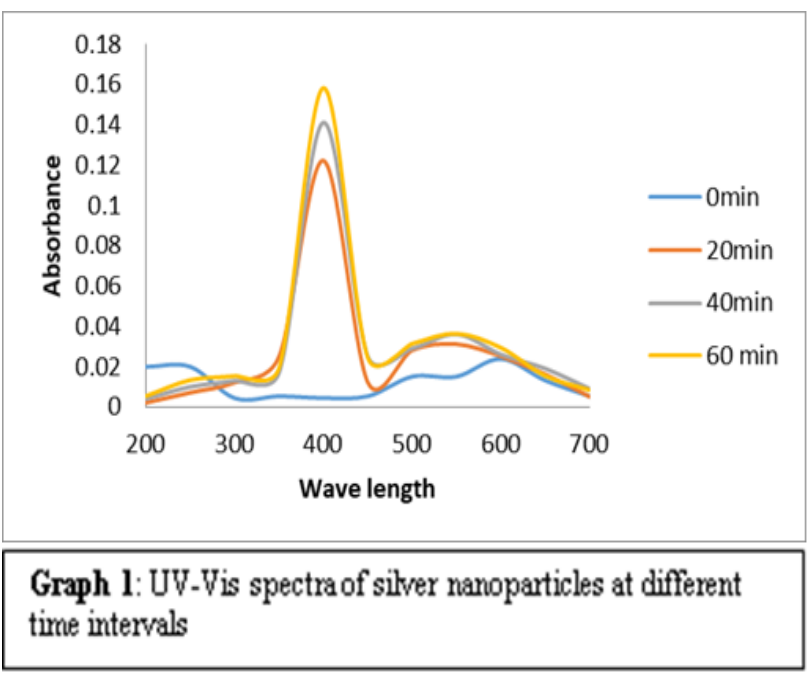

recorded after incubating the plates for 24 hours at $37^{\circ} \mathrm{C}(9)$.

\section{Antioxidant assay \\ DPPH assay}

Antioxidant activity was determined by BrandWilliams method (11) with a slight modification. The absorbance of the reaction mixture was measured at $517 \mathrm{~nm}$ after incubating at room temperature in dark condition for $30 \mathrm{~min}$. using ascorbic acid as a standard. The percentage of antioxidant activity was calculated using the following formula.

\section{RESULTS}

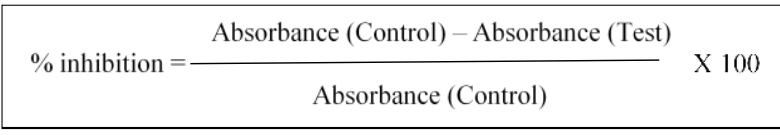

\section{UV-visible spectroscopy}

The synthesis of silver nanoparticles from plant leaf extracts

The colour changed to brown due to the addition of $1 \mathrm{mM} \mathrm{AgNO}_{3}$ to the plant extracts. There was no colour change observed in $0 \mathrm{~min}$. After 2-4 hours, colour of the solution changes from green to brown, the UV-Vis absorption spectra were studied at 300 to $700 \mathrm{~nm}$, which confirmed the presence of Ag-NPs (Fig. 2). The absorption peak of silver nanoparticles is at $438 \mathrm{~nm}$.

Different contact time and Tm (temperature) affect the synthesis of nanoparticles (Graph 2) and show the UV-absorption spectra of Ag-NPs at different time in the range of $20-60 \mathrm{~min}$ and $20-60^{\circ} \mathrm{C}$. The temperature increased the change in the colour of the solution rapidly. When the $\mathrm{Tm}$ of the reaction mixture is increased, an increase in the synthesis of silver nanoparticles is logical which is due to the amplification in a decreased rate of $\mathrm{Ag}^{+}$ions and the solution colour turning from brown to dark brown within $3 \mathrm{~min}$ and decrease in particle size. An increase in $\mathrm{Tm}$ above $40-60^{\circ} \mathrm{C}$ increases the absorbance peak (15).

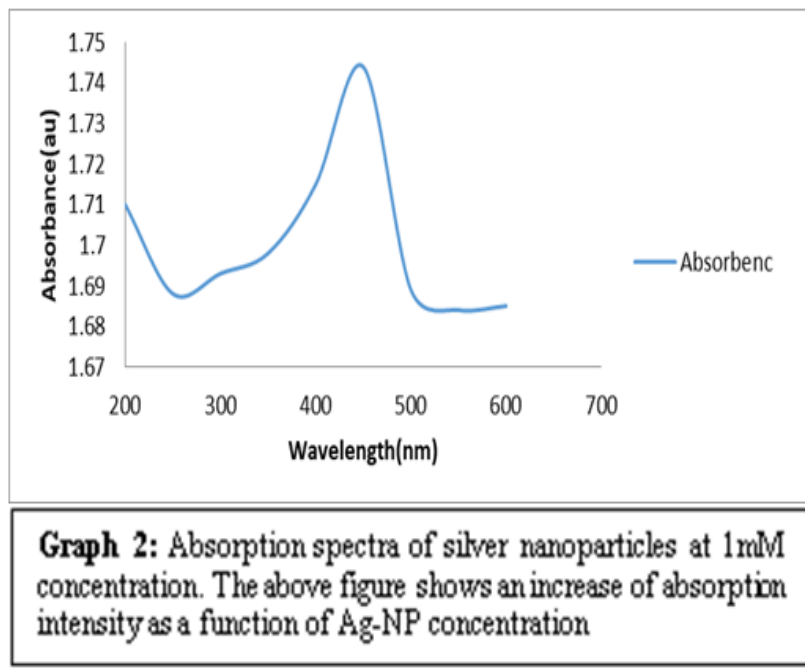




\section{FTIR}

FTIR measurement was used to find out the interaction of silver ions with the bioactive components present in the plant leaf extracts that are responsible for stabilizing of Ag-NPs. The absorption bands in the FTIR spectrum indicate the occurrence of functional groups in the silver nanoparticles (Fig. 2). FTIR results show the band in the range of 3500$500 \mathrm{~cm}^{-1}$; different band range represents different functional groups (Table 1).

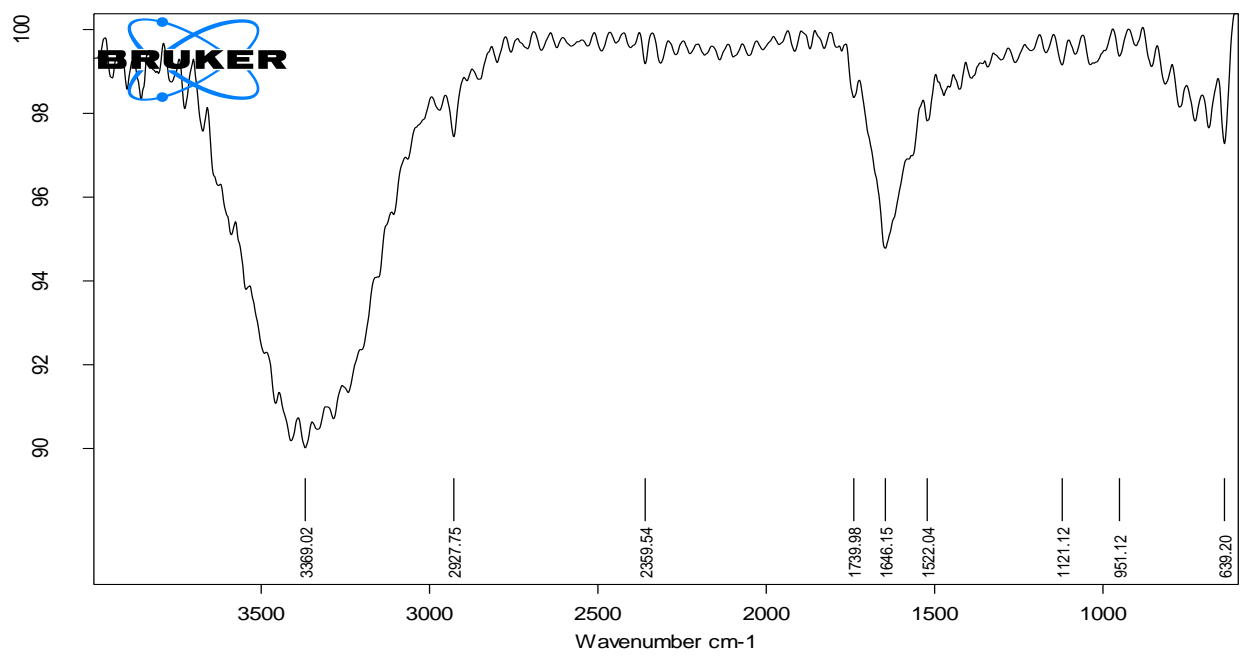

Fig. 2: FTIR spectrum of Ag-NPs

Table 1: FTIR peak values and functional groups of Ag-NPs

\begin{tabular}{|c|c|c|c|c|}
\hline Extracts & Peak Value & $\begin{array}{l}\text { Functional } \\
\text { Group }\end{array}$ & $\begin{array}{c}\text { Functional Group } \\
\text { Name }\end{array}$ & Vibrations \\
\hline \multirow{9}{*}{$\begin{array}{l}\text { Synthesis of } \\
\text { nanoparticles }\end{array}$} & 639.20 & C-I & Haloalkane & Stretch \\
\hline & $970-799$ & $\mathrm{C}-\mathrm{C}$ & Alkane & - \\
\hline & $\begin{array}{c}1121 . \\
21\end{array}$ & $\mathrm{C}-\mathrm{F}$ & Haloalkane & Bending \\
\hline & $2921-2852$ & $\mathrm{C}-\mathrm{H}$ & Alkane & Stretch \\
\hline & $1463-1382$ & $\mathrm{C}-\mathrm{O}, \mathrm{C}-\mathrm{F}$ & $\begin{array}{l}\text { Alcohols, ethers, esters, } \\
\text { and haloalkane }\end{array}$ & $\begin{array}{l}\text { Bend out- of- } \\
\text { plane }\end{array}$ \\
\hline & 1633.57 & $\mathrm{C}=\mathrm{C}$ & Alkene & - \\
\hline & 1721.07 & $\mathrm{C}=\mathrm{O}$ & Acid, saturated & - \\
\hline & $2921-2852$ & $\mathrm{C}-\mathrm{H}$ & Alkane & Stretch \\
\hline & 3449.61 & $\mathrm{O}-\mathrm{H}$ & alcohols and Phenols & Stretch \\
\hline
\end{tabular}

\section{SEM}

The morphology of silver nanoparticles was examined using SEM and observed the reduction of $\mathrm{AgNO}_{3}$ with plant leaf extract. The SEM results also depicted the morphology and size details of Ag-NPs with high-density. An assembly of spherical and uniform Ag-NPs were observed (Fig. 3).
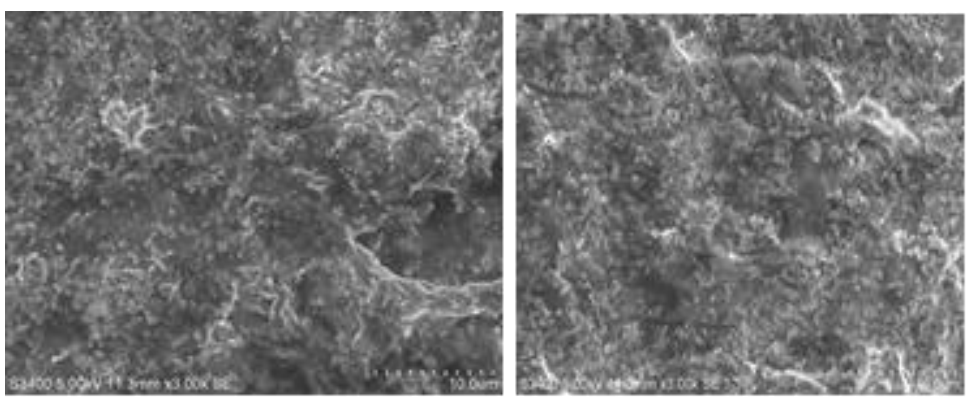

Fig. 3: SEM image of the biosynthesized silver nanoparticles

\section{Antimicrobial activities}

Silver nanoparticles were tested for antibacterial activity against both Gram-positive and Gramnegative pathogenic bacteria. Green synthesized silver nanoparticles exhibited good antibacterial activity against the pathogenic bacteria (Table 2 and Fig. 4). The silver nanoparticles synthesized using methanolic leaf extract showed good antibacterial activity compared to those synthesised using water extract of leaf. 

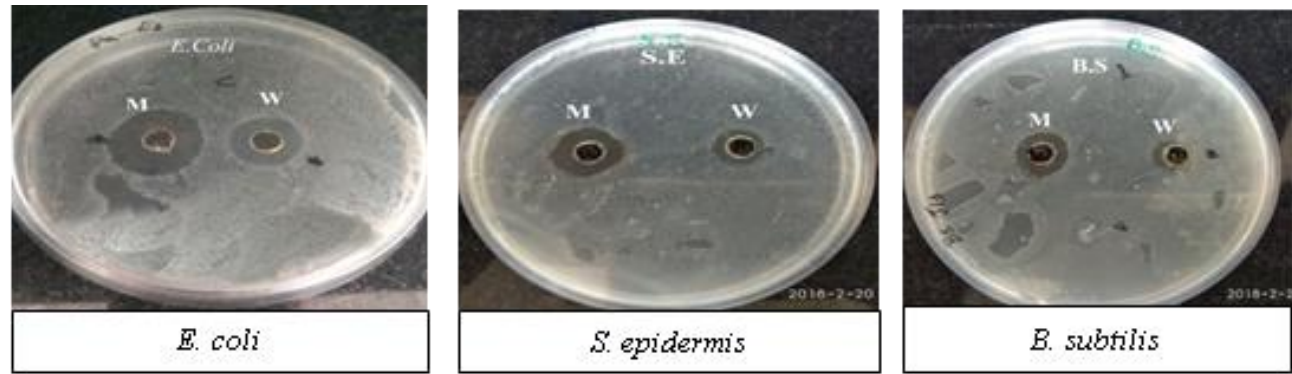

Fig. 4: The methanol $(\mathrm{M})$ and water $(\mathrm{W})$ extracts of Ag-NPs solution at $(15 \mu \mathrm{L})$ different concentration

Table 2: Zone of inhibition (in $\mathrm{mm}$ )

\begin{tabular}{|c|c|c|c|}
\hline Sl. no & Name of the Bacteria & Methanol extract & Water extract \\
\hline 1 & E. coli & $4 \mathrm{~mm}$ & $2 \mathrm{~mm}$ \\
\hline 2 & S. epidermis & $2 \mathrm{~mm}$ & $1 \mathrm{~mm}$ \\
\hline 3 & B. subtilis & $3 \mathrm{~mm}$ & $1 \mathrm{~mm}$ \\
\hline
\end{tabular}

\section{Antioxidant activity}

The antioxidant activity of silver nanoparticles was evaluated by DPPH radical scavenging method. A potent antioxidant activity was observed, and the activity was increased in a dose dependent manner (Graph 3).

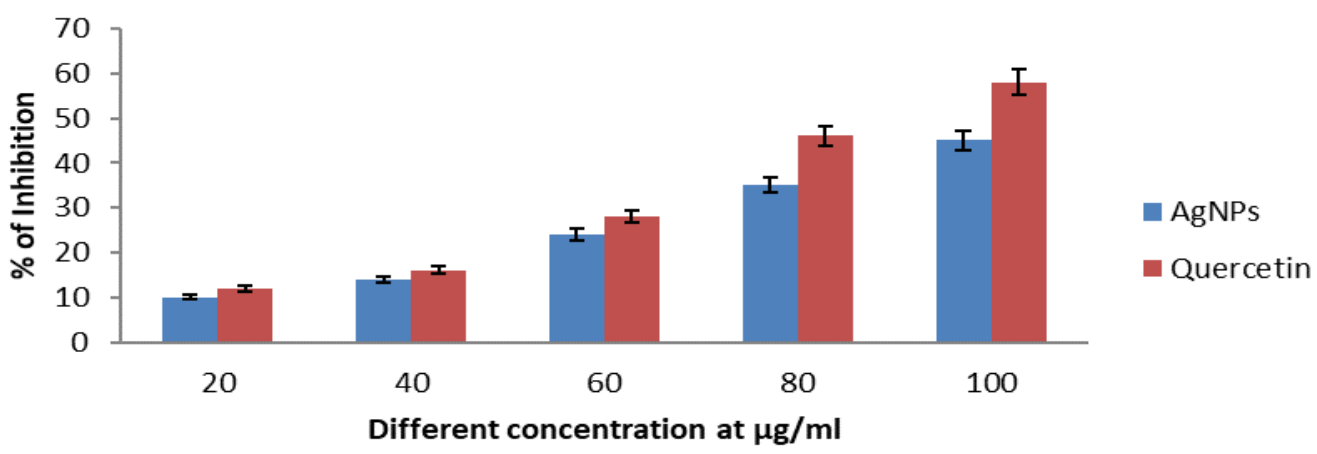

Graph 4: AgNPs at different concentrations and compared with positive control

\section{DISCUSSION}

Green synthesis of nanoparticles has been considered as one of the hopeful methods for synthesis of nanoparticles because of their low toxicity, biocompatibility and eco-friendly nature $(3,17)$. The colour of silver nanoparticles changed to brown due to the addition of $1 \mathrm{mM} \mathrm{AgNO}_{3}$ to the plant extracts. The absorption peak of silver nanoparticles is at 438 nm.

UV-vis spectra were used to observe the effect of contact time and optimum temperature on Ag-NPs concentration in the reaction mixture at altered optimum intervals of the time period. The solution was observed for colour change (Fig. 1 and Flow chart 1). The intensity of UV-vis absorption peaks was increased gradually and then became constant because the concentration of silver nanoparticles was initially increased with increase in temperature and different contact time. Different contact time was obtained for this experiment between 40-60 minutes (Graph) which showed a very broad absorbance peak showing an increasing particle size $(10,18)$.

FTIR spectrum showed different peak positions at 639.20, 961.20, 1121, 1522.04, 1646.15, 1739.98,
2359.98, 2927, $3369 \mathrm{~cm}^{-1}$. The similarities between the spectra with some marginal shifts in peak position clearly indicates the presence of the residual plant extract in the sample as a capping agent to the silver nanoparticles. The peak located at the different range and functional groups of each peak (Fig. $3 \&$ Table 1). Antimicrobial activity of Ag-NPs was carried out against pathogenic bacteria (Fig. $4 \&$ Table 2). The synthesized Ag-NPs exhibited excellent antibacterial activity against both Gram-positive and Gram negative such as $S$. aureus and E. coli bacteria (19, 20). The nanoparticles are also utilized in the field of solar energy conversion, and water treatment. Further, in biomedical application, silver nano particles are being used for anticancer, antiinflammatory activity.

\section{CONCLUSION}

The green synthesis of Ag-NPs from Olea dioica Roxb., leaf extract is simple, cost-effective, fast, environment-friendly and the plant leaf phytochemical acts as the reducing agent. The silver (AgNPs) nanoparticles synthesized by the one-pot green synthesis method are proved to be potential reagents in various medical and industrial applications. 


\section{REFERENCES}

1. Yasin, S. A., Liu, L. A, Yao, J. Biosynthesis of silver nanoparticles by bamboo leaves extract and their antimicrobial activity. Journal of fibre bioengineering and informatics 2013; 6(1): 77-84.

2. Ahmed, Y., and Ikram, S. silver nanoparticles: one-pot green synthesis using Terminalia arjuna extract for biological application $\mathrm{j}$ nano-med nanotechnology 2015; 6(4): 1-6.

3. Kumar, R., Ghoshal, G., Jain, A., and Gyal, M. Rapid green synthesis of silver nanoparticles (AG-NPs) using (Prunuspersica) plant extract: exploring its antimicrobial and catalytic activities. Nano med nanotechnology 2017; 8: 4.

4. Verma, A., Mehta, M. S., Controllable synthesis of silver nanoparticles using neem leaves and their antimicrobial activity Journal of Radiation Research and applied science. 2013; 9: 109-115.

5. Manjunath, H. M., Chandrashekhar, G. J., Characterization, antioxidant and antimicrobial activity of silver nanoparticles synthesized using marine endophytic fungus- Cladosporium cladosporioides. Biochemistry and Biophysics Reports. 2017.

6. Banerjee, P., Satapathy, M., Mukhopadhyay, A., and Das, P. Leaf Extract Mediated Green Synthesis of Silver Nanoparticles from Widely Available Indian Plants: Synthesis, Characterization, Antimicrobial Property, and Toxicity Analysis. Bioresources and Bioprocessing. 2014; 1: 3.

7. Akshay, K. R., Sudharani, N., Anjali, K. B., and Deepak, T, M. Biodiversity and Strategies for Conservation of Rare, Endangered and Threatened Medicinal Plants. RRJPP. 2014 2; (3): 1-5.

8. Sringeswara, N., Shivanna, M. B., And Gowda, B. Floristic Diversity InKudremukh National Park, Western Ghats, Karnataka, 2015; 1-5.

9. Kaviya, S., Santhanalakshmi, and Viswanathan, B. Green Synthesis of Silver Nanoparticles Using Polyalthia longifolia Leaf Extract Along With D-Sorbitol: Study of Antibacterial activity Hindawi Publishing Corporation Journal of Nanotechnology Volume 2011: 1-5.

10. Elgorban, A. M., Al-Rahmah, A. N., Sayed, S. R., Hirad, A., Mostafa, A. A. F., Bahkali, A. H. Antimicrobial Activity and Green Synthesis of Silver Nanoparticles Using Trichoderma viride Biotechnology \& Biotechnological Equipment, 2016; 30 (2): 299-304.

11. Verma, A., Arya, A., Joshi, P. Activity of Silver Nanoparticles Synthesized Using Aqueous Leaf Extract of Sonchus asper Against Potential Human Pathogenic Bacteria. World Journal of Pharmacy and Pharmaceutical Sciences. 2016; 5(10): 1154-1166.

12. Rao, A. A Study on Antioxidant and Cytotoxic Properties of Olea dioica Roxb. Crude Extract and Its Pure Compound Collected from Western Ghats, Karnataka, India. Asian Journal of Pharmaceutical and Clinical Research. 2017; 10(2): 356-67.

13. Erjaee, H., Rajaian, H., and Nazifi S. Synthesis and Characterization of Novel silver Nanoparticles Using Chamaemelum Nobile Extract for Antibacterial Application adv. Nat. Sci.: Nanosci. Nanotechnol. 2017; 8(9): 1-10.

14. Li, G., Dan, H., Qian, Y., Guan, B., Gao, S., Cui, Y. et al., Fungus-Mediated Green Synthesis of Silver Nanoparticles Using Aspergillus Terreus, Int. J. Mol. Sci. 2012; 13: 466476.

15. Khalil, M. M. H. Green synthesis of silver nanoparticles using olive leaf extract and its antibacterial activity. Arab J Chem. 2013; 7: 1131-39.

16. Saravana Kumar, A., Ganesh, M., Jayaprakash, J., Tae, H. Biosynthesis of silver nanoparticles using Cassia tora leaf extract and its antioxidant and antibacterial activities. J IndEng Chem.2015; 28: 277-281.

17. Khatoona, A., Khana, F., Ahmad, B. N., Shaikha, S., Mohd, S., Rizvic, D. et al., Silver Nanoparticles from Leaf Extract of Mentha piperita: Eco-Friendly Synthesis and Effect on Acetylcholinesterase Activity Life Sciences 2018; 209: 430 434.

18. Sulaiman, C. T. and Gopalakrishnan, V. K., Radical Scavenging and In-Vitro Hemolytic Activity of Aqueous Extracts of Selected Acacia Species. Journal of Applied Pharmaceutical Science. 2013; 3(03): 109-111.

19. Sana, S. S., Badineni, V. R., Arla S. K., Naidu B. V. K. Ecofriendly synthesis of silver nanoparticles using leaf extract of Grewia florescences and study of their antimicrobial activity. Mater Lett. 2015; 145: 347-350.

20. Padalia, H., Moteriya, P., Chanda, S. Green synthesis of silver nanoparticles from marigold flower and its synergistic antimicrobial potential. Arab J Chem. 2015; 8(5): 732-741. 